\title{
CRITICAL APPROACH OF DIGITAL FOOTPRINTS TO STUDY SPATIAL PRACTICES OF URBAN TOURIST AREAS: A CASE STUDY OF INSTAGRAM DATA IN BIARRITZ, FRANCE
}

\author{
MÉLANIE MONDOํ, MATTHIEU NOUCHER ${ }^{2}$, GRÉGOIRE LE CAMPION², \\ LUC VACHER $^{1} \&$ DIDIER VYE ${ }^{1}$ \\ ${ }^{1}$ Littoral Environnement et Sociétés (LIENSs), CNRS/La Rochelle University, France \\ ${ }^{2} \mathrm{CNRS} /$ Bordeaux Montaigne University, France
}

\begin{abstract}
The rise of digital footprints has created a number of promises and expectations for the study of territorial dynamics, particularly those of tourist cities. These footprints would make the observation of visitors' spatial practices possible and make up for the lack of information on these practices at an urban scale. Thus, many studies use data from social networks to study the touristic space at different geographical scales. These studies provide several types of visualisations based on this data, thus making it possible to represent and show a supposedly new touristic space-time - from the heat map to the dashboard, the digital footprints are displayed as processed, aggregated, calculated and smoothed. All these transformations - resulting from algorithmic black boxes that do not allow a precise understanding of the methodologies (often complex and approximate) - are often not very transparent. Consequently, the technicality and opacity of this data make necessary the development of critical approaches that allow the deconstruction of these new mapping registers. Based on data collected on a widely used social network, Instagram, we wish to question digital footprints as a potential tool to observe tourist practices, by going back through the data genealogy, from the map to the footprint. Our approach consists of going back to the initial data and their associated metadata, in order to explore two fundamental dimensions, conditions pre-requisite for more complex explorations: time and space. Therefore, we collected a corpus of metadata from photographs published on Instagram between 2016 and 2018 in Biarritz, France, which we analyse following these two axes. Through this exploratory study, we will demonstrate that this data, though very rich, presents a certain number of limits, whether in terms of access to the data itself or its spatiotemporal precision.
\end{abstract}

Keywords: digital footprints, spatial practice, tourist city, critical data studies.

\section{INTRODUCTION}

In the spring of 2020, in the midst of the Covid-19 pandemic, a debate is raging over the geolocation of mobile phones and their potential role in optimising management of this crisis. Although the technology is by no means new, its application does however lie at the centre of controversy with some seeing it as an essential device for monitoring and controlling the spread of the virus while others denounce a freedom-destroying technology that opens the door to widespread individual surveillance [1]. In fact, an Italian research firm studied lockdown breaches on the basis of Instagram stories [2], in other words, the collections of content on user profiles, put online for a period of 24 hours and normally intended to showcase spontaneous moments, so more or less in real time.

The pandemic has made it possible to highlight the debates but also the promising prospects concerning the use of digital footprints. Their profusion is tending to promote the idea that once gathered, they would be able to meet the need for monitoring of territorial dynamics [3], [4]. In the field of tourism, these footprints would make it possible, in particular, to observe the spatial practices of visitors, so making up for a lack of information, especially within urban spaces [5]. In the context of sustainable cities, this information is 
important as it enables better management of tourist flows, and thus their impact on their direct environment.

Based on this prospect, we wanted to study the effective potential of digital footprints for the study of tourist dynamics in the city and, more especially, the supposed contribution of footprints from social media. On the basis of digital footprints, what can we say about tourist space-time in the city, in other words, the spatial and temporal dynamics associated with tourism in a city?

To answer this question, we suggest looking at basic data before it is mapped. In fact, although occasional entities, digital footprints are regularly represented after being processed, calculated, aggregated and smoothed by multiple geovisualisations including heatmaps and are becoming the new standard. The often complex and sometimes approximate methodologies associated with these mapping processing operations are rarely explained. Consequently, the technicality and the opacity of this data require the development of critical approaches that make it possible to deconstruct these new mapping. Our research is inspired by critical data studies that decipher the challenges of the digital revolution by deconstructing web infrastructures and data [6]. Thus, we propose starting from data collected on Instagram, a social medium that is widely used, particularly in the context of tourism practices, by going back up through the genealogy of the data: maps offering visualisations of social media data with footprints actually submitted by users.

To this end, we are interested in the data as it is left by the users and indexed by the platform: dot maps that locate photos, tags entered by users and metadata associated by the system at the time of online submission. Our objective is to start from these basic features to assess their effective potential in the study of an urban tourist space-time. Firstly, we analyse the challenges and value of the use of digital footprints, particularly those from social media, in order to study two essential dimensions of tourism: time (travel, visitor numbers, etc.) and space (places visited, photographed). In a second step, we detail our methodology associating exploration of data platforms and observations of field practices from the case study of Biarritz, a seaside resort in the southwest of France. The third part presents the results of the data analysis to assess the strengths and limitations of these footprints in order to understand the spatio-temporal dimension of the spatial practices of the tourist space. We will conclude by highlighting the discrepancies between the technological prospects and the actual potential of the available data.

\section{DIGITAL FOOTPRINTS FOR THE STUDY OF TOURIST PRACTICES}

The profusion of digital footprints has fed into numerous works on the geographic study of tourism practices (Section 2.1). We propose to work within the field of critical data studies in order to examine the actual potential of this type of data in studying the spatial dynamics of the tourist city (Section 2.2).

\subsection{Digital footprints, the new "holy grail" of tourism studies?}

Digital technology explores the functioning of social sciences in terms of their methods, paradigms and theoretical orientations as well as their purposes [7]. Geography does not escape these transformations, digital technology having become, in the space of a few years, the purpose, subject and means of study. Over the past decade, a great deal of research has focused on the geoweb - the aggregate of space technology and georeferenced information organised and transmitted over the Internet and accessible through the space media - and has concentrated on the development of Volunteered Geographic Information (VGI) [8]. With this expression, Goodchild translates the technical and organisational recompositions that 
have shaken up the production of geographic data in recent years with the development of the Internet and what he terms "citizen sensors". The individual is now at the heart of data production through the exponential use of connected objects. Digital footprints have therefore multiplied in recent years and are increasingly used in research in the field of geography [9].

The quantity but, above all, the nature of the geolocated data now available has undergone a profound change, compared to data traditionally obtained from official statistics. In the field of tourism, these unprecedented sources come on top off the numerous field surveys to study tourist numbers, tourist satisfaction or even tallying of admissions at paid sites. The emergence of VGI, particularly from social media like Instagram, Flickr or Twitter, the contents of which are strongly linked to leisure activities, opens up dizzying prospects for the geolocated measurement of tourism practices. In fact, countless statistical footprints are now associated with our digital practices, which are themselves intertwined with our tourist activities: searches run on web browsers to book a hotel, online sharing of our photos or videos, requests on applications to find sites or optimise our trips, online reservations for excursions, online rental of bikes, etc. As Tovar [10] points out: "it is therefore now possible to perceive, measure and quantify the reality of our lives as never before, and most notably the geographic dimension". Digital communications publicise an increasing part of our leisure practices and so produce masses of decentralised data of unprecedented abundance.

In the context of this study, we have chosen to focus on footprints from social media. Social media data provides access to more spontaneous information than conventional surveys, since the information collected is not dependent on a set of questions that could obscure certain practices. In fact, this "geo-crowdsourcing data" [11] has a volume, a precision and a semantic abundance such that research projects calling on this data are numerous for studying the city and the geographical practices of tourism [5], [12]. It makes it possible to map tourist mobility [13], [14], the spatial practices of tourists [15]-[17], to explore new forms of representation of tourist movements [17]-[20], or even identify attractive places [21]-[23]. It therefore seems possible to use this data to offer an alternative visualisation of the space-time of a tourist city.

\subsection{Going beyond the "black box" effect to assess the advantages and} limits of digital footprints

Although the heuristic potential of the footprints is effective, the multiplication of geovisualisations making it possible to represent the spatial practices resulting from digital footprints has also given rise to some reservations [24]. To date, critical approaches to big data mainly focused on the methodological biases associated with data processing but also on the social, political and ethical issues of these systems or on the remaining information deficiencies [25]-[27].

In fact, these critics make the observation that the mapping of footprints is rarely accompanied by the raw data on which the analyses are based. The results are often presented in the form of geovisualisation which has a tendency to conceal the basic data. In fact, (geo)visualisation occupies a central place in this research: for Girardin et al. "mapping and visualization are critical first steps to interpreting and explaining digital footprints" [14]. Beaude [28] also emphasises that "the main issue surrounding digital footprints is one of visibility". Part of the research effort is now focused on making aesthetically pleasing representations, in the form of heatmaps (Fig. 1). 


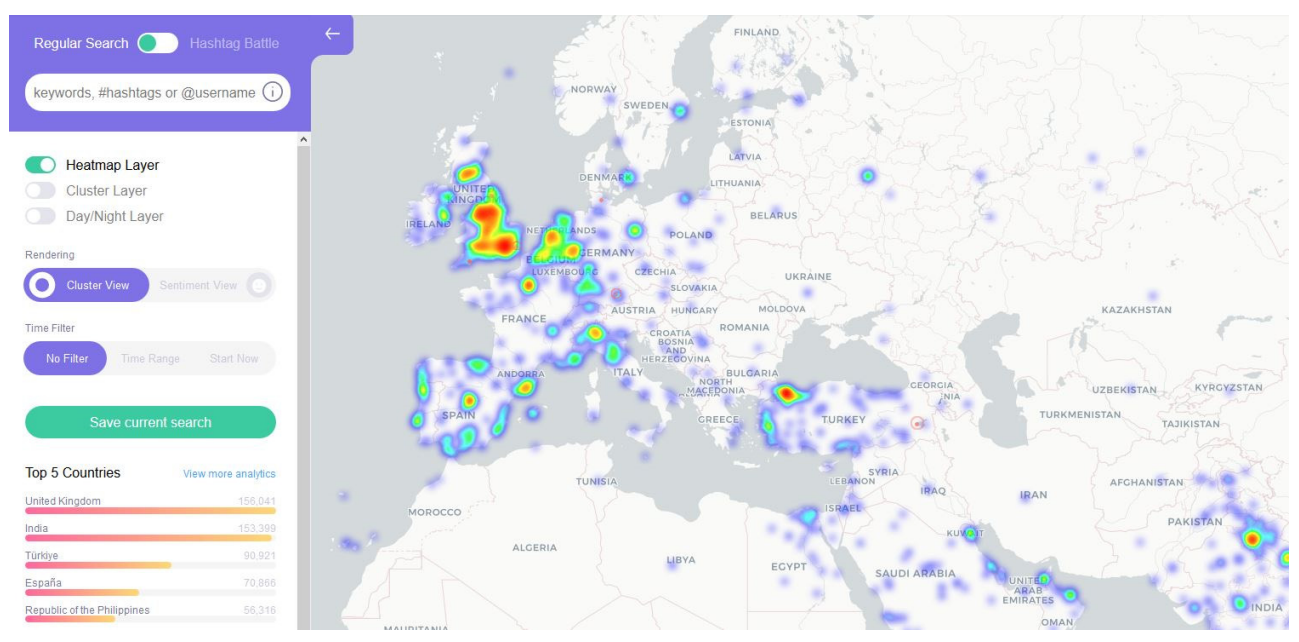

Figure 1: Heatmap of aggregated tweets in real time [43].

These representations show smoothed data, suggesting an impression of continuity of the mapped phenomena. The footprint, which is generally marked spatially in the form of a dot made up of the geographical coordinates of the content disseminated (texts, tags, photos, videos), becomes linear or even zonal, under the effect of these geovisualisations. These maps highlight areas with high visitor numbers or so-called hotspots whose precise definition is rarely discussed. Thanks to digital tools, it has also become easy to create dynamic maps, revealing the trend for the territory according to a temporal parameter. Aggregation, interpolation and extrapolation methods are at the heart of the techniques used here.

Although meticulous and popular, these maps raise questions in terms of research methodology and reproducibility [24]. Indeed, given the lack of transparency of the algorithms, it is difficult to escape a kind of "black box" effect: the processing operations performed on the data when loading on the platform, the increasingly difficult and limited access to the data, the poor documentation concerning this available information are all issues and barriers to take into account.

In order to assess the potential of digital footprints to improve understanding of the spacetime of tourism in the city, we therefore propose deploying a critical study of one of these algorithmic black boxes. By drawing inspiration from critical data studies, we seek to move away from "ready-made" technoscientific promises and maps and immerse ourselves in data infrastructures to assess the strengths and limits of these new corpora. By relying, in particular, on the advances of mapping and critical GIS, critical data studies aim to reposition at the centre of scientific debates a renewed critical approach to data, from its collection through to its processing and then its use [29]. By focusing more specifically on the profusion of geovisualisations that arise from big data, they question the methodological biases potentially linked to the processing and spatialisation of data (sometimes summary, incomplete or approximate) and their effects in terms of socio-spatial inequalities or the construction of territorial fantasies.

It is in this spirit that we are conducting this empirical study. By analysing the raw data available within a social medium used by tourism players, we seek to assess its strengths and limitations in order to study the spatial practices of the urban tourist space. To that end, it strikes us as essential to decipher the digital footprint as close as possible to its creation, 
upstream of the maps which publicise them. The originality of our approach lies in our decision not to limit ourselves to a deconstruction of the finished products (maps and other geovisualisations), but instead to follow the trail back to the sources: the data - photos and tags entered by the user - and metadata - information automatically associated with the data by the system - in order to analyse its effective potential for studying tourist cities.

To do so, we examine the available data according to the two dimensions of time and space. Over time, we seek to question what the data tells us about the temporal variations in the visitor numbers at places. Through geographic information, we seek to question what the data tells us about the visibility of places used, frequented, photographed and shared.

\section{STUDYING THE TOURISM SPACE-TIME VIA INSTAGRAM: FROM GEOTAG TO DATA RETRIEVAL}

\subsection{Instagram: at the heart of tourist practices}

Long before the advent of digital technology, it was shown that photography was at the heart of the "tourist gaze" [30]: whether it is that of tourists and their desire to keep a momentum of their trip or to be photographed in attractive places, or that of economic players who want to showcase their territories through the promotion of a tourism "product" [31]. Photography therefore contributes to the profusion of material images in the field of tourism. These images therefore have a high performative value [32], [33] and since "The images are there to make the world peaceful, secure, welcoming and easy to understand" [34], the iconography has aimed to be positive and aesthetic while helping to make places desirable since tourism first began. Facilitated by a growing storage capacity, digitisation contributes to "compulsive photo taking" [32]. Social media allow for easy sharing of holiday images on a large scale. The mass of data posted on photo-sharing platforms makes it possible to capture recurrences in the subjects of these images.

Instagram is a social medium allowing everyone to produce, share and tag photographs, videos and images in large numbers. Created in 2010 and bought by Facebook in 2012, the platform continues to see its number of users grow. On a global scale, the medium has more than one billion active users every month in 2020, including 18 million in France [35]. Praised and criticised in equal measure, Instagram has become essential, especially in the tourism sector. In fact, the site contributes to the high visibility of tourist places [36]. The fact that it is free and user friendly thanks to the smartphone application makes it a tool for an a priori instantaneous dissemination of billions of photographs that can potentially be seen by millions of people. In addition, for socio-economic tourism players, the platform is a communication and marketing tool for tourists, whether actual or potential. Although, extremely popular with young people, especially 15-35 year olds, the use of Instagram is not limited to the dissemination of holiday snaps. This diversity of user profiles and associated practices is to be borne in mind in the results that we will present and will require a subsequent study. However, while not all Instagram users are tourists, we start from the assumption that in a seaside city with a strong tourist dimension, many use it to record their spatial practices.

\subsection{Biarritz, a seaside city with a strong tourist dimension}

Studying digital footprints on Instagram makes it possible to explore their potential for studying the temporal variation of visitor numbers and the visibility of places. To this end, we have decided to focus on the city of Biarritz. Located on the Basque coast in the southwest 
of France, it has been a centre of seaside tourism since the 19th century and has gained in international influence, largely thanks to the practice of surfing, of which it is the European centre [37].

Large-scale bathing practices induce seasonal visits. According to the official website of the city of Biarritz [38], the census by the INSEE (French national statistics bureau) revealed a winter population of 25,404 inhabitants in 2017 for an estimated summer population of 110,000 inhabitants. Although the city is marked by a strong seasonality, there are certain major events all year round, like an international surfing competition held in May on the city's main beach (Grande Plage).

This makes Biarritz an ideal case study for examining the uneven visibility of tourist places through a social medium such as Instagram. Indeed, the city is organised around emblematic places located around the Grande Plage such as the Casino Barrière, the Grand Hôtel, the Rocher de la Vierge or the Biarritz lighthouse. All of these places thus participate in the tourist imaginary of the city. It will then be interesting to compare the visibility of the places shared on Instagram compared to this fantasy.

We therefore make the assumption that the seasons, the events or the emblematic places constitute the space-time of a tourist city such as Biarritz and so should be visible through Instagram data.

\subsection{Return to the source: Instagram data retrieval}

In 2020, Instagram allows you to retrieve your own data as a network user. An API (Application Programming Interface) permits access to a data flow proposed by an application or a website. It is a commonly used method for accessing data from web platforms. The closing of APIs to the general public or restricted access thereto is an increasingly common phenomenon in social media, meaning that new methods of data collection need to be found. The proposed API makes it possible either to retrieve your own data, or to retrieve the 20 most recent posts by ten users. In order to conduct a Biarritz-wide study, it was necessary to use a third-party application.

We used a dedicated open-source software program, Instaloader (available on https://instaloader.github.io/), developed with the Python programming language, which allows public posts to be downloaded from Instagram using a keyword (hashtag), a place (geotag) or a profile (user). Data is retrieved in three formats: the post's image (.jpg), the legend (caption) in .txt format, and the post's metadata (.json).

Our data was therefore filtered using the names of geotags associated with Biarritz. On Instagram, this marking is done by the user who names the place in question, without entering geographic coordinates. The place is chosen by the user but can be suggested by the application if the geolocation is activated or according to the user's most recent inputs. Adding a geotag to your post increases its visibility on the platform. The list of geotags used is selected by an algorithm specific to Instagram. Not having access to the selection criteria of the algorithm, it is not possible to affirm that this list groups together all the geotags of Biarritz, nor to be sure of the geographical selection criteria. In addition, we have decided to limit our data collection in time between 2016 and 2018. In fact, in 2016, Instagram scrapped a way of geographically tagging its posts by only offering textual input [39]. In addition, the collection of data from the corpus having taken place in spring 2019, that year is not considered in order to work on full years.

The algorithm proposes a list of 1,000 geotags, reduced to 803 for the period studied. However, these geotags have different spatial granularities: from the Basque Country to the Rocher de la Vierge, passing through the Bayonne-Anglet-Biarritz conurbation or Biarritz. 
These geotags may contain input errors. Since our geotags are not associated with precise geographic information, geocoding must be done. For this purpose, we use the tool made available by a French government structure for data sharing (Etalab) to geocode the majority of the database. Finally, the few missing geotags are georeferenced manually.

Our database contains 539,935 posts, including 223,850 geolocated before analysis. The documentation made available by Instagram does not detail all of this data. The description of the variables (Table 1) is the result of our research. Table 1 summarises this reverse engineering that has become essential in the absence of documentation.

Table 1: Metadata associated with Instagram photographs.

\begin{tabular}{|c|c|c|}
\hline Variable name & Description & Example \\
\hline Id_geo & $\begin{array}{l}\text { Identifier added by us } \\
\text { corresponding to the file in which } \\
\text { the data was downloaded }\end{array}$ & $\begin{array}{l}\text { Bardumarchede } \\
\text {-biarritz.json }\end{array}$ \\
\hline Geotag & $\begin{array}{l}\text { Name of the geotag associated } \\
\text { with the retrieved photograph }\end{array}$ & Bar du Marché \\
\hline Node_id & Unique post identifier & $\begin{array}{l}1417400626828 \\
247741\end{array}$ \\
\hline Is_video & $\begin{array}{l}\text { True/False: this lets you know if } \\
\text { the post is a video rather than a } \\
\text { still image }\end{array}$ & False \\
\hline Shortcode & $\begin{array}{l}\text { Shortened post identifier code, } \\
\text { appears to be used in the URL }\end{array}$ & BOrnlxCg4K9 \\
\hline Comments_disabled & $\begin{array}{l}\text { True/False regarding the opening } \\
\text { of comments on the post }\end{array}$ & False \\
\hline Taken_at_timestamp & $\begin{array}{l}\text { Timestamp (universal format for } \\
\text { sharing date and time) } \\
\text { corresponding to the placing on } \\
\text { line of the post }\end{array}$ & 1483187343 \\
\hline Video_view_count & $\begin{array}{l}\text { Number of video views if it } \\
\text { concerns a video }\end{array}$ & \\
\hline Thumbnail_resources & $\begin{array}{l}\text { Information about the miniature } \\
\text { of the photograph }\end{array}$ & \\
\hline Owner_id & $\begin{array}{l}\text { Unique identifier of the account } \\
\text { having posted }\end{array}$ & 444619463 \\
\hline Width/height dimensions & Dimension of the photograph & $350 \times 350$ \\
\hline Edge_liked by_count & Number of "likes" on the post & 231 \\
\hline Edge_media_to_comment_count & Number of comments on the post & 4 \\
\hline Edge_media_preview_like_count & $\begin{array}{l}\text { No information on the meaning of } \\
\text { this indicator }\end{array}$ & 231 \\
\hline Edge_media_to_caption & Caption of the post & $\begin{array}{l}\text { \#biarritz } \\
\text { \#croquette } \\
\text { \#nouvelan }\end{array}$ \\
\hline
\end{tabular}

The rapid modification of the data access rules (with the restrictions linked to the closing of the API), and the absence of documentation, make it difficult to use this data and reproduce a research process. The rapid development of the technological choices made by these 
proprietary platforms is one of the key factors to take into consideration ahead of any research. Nevertheless, the availability of an open source program making it possible to circumvent these obstructions, made it possible to constitute our database. The objective is now to explore them in order to better understand the tourist space-time of Biarritz between 2016 and 2018.

\section{QUESTIONING THE SPACE-TIME OF THE TOURIST CITY OF BIARRITZ}

We will firstly question the temporal marking of variations in visitor numbers (Section 4.1) before questioning the meaning of geotags and what they tell us about the visibility of places in the tourist city (Section 4.2). We start by recalling the supposed contributions of the digital footprints before opening their black box in order to clarify their interpretation limits but also the new opportunities they seem to offer.

\subsection{Examining the temporal variations of visitor numbers in Biarritz from} the digital footprints

\subsubsection{Supposed contributions}

What do the digital footprints tell us about the temporal variation of visitor numbers in Biarritz? Biarritz is a city marked by a strong seasonality and by major events attracting a large population. We therefore make the assumption that these expected peaks in visitor numbers are found in our exploration.

In fact, the abundance of digital data gives rise to hopes of observing a "city 24/7" [40]. Thus, with the digital footprints, it would be possible to have access to the finest temporal coverage in order to see the visitor numbers in the places vary. Instagram makes it possible to share your photographs in real time, at the very moment of taking them. In an urban tourist space, this would permit, by aggregation, visualisation of the temporal variations of the number of tourists visiting the city according to different granularities, namely interannual, seasonal, weekly and daily. It would therefore be possible to visualise the "urban pulsations", "expression of intersecting time frames which make up urban rhythms" [41] allowing the attractiveness of different parts of the city over time to be shown.

By associating temporal information with geotag information, it becomes possible to study temporal variation on two scales: that of the city on the one hand and that of the tourist sites on the other. In doing so, it is possible to distinguish similarities or differences in the number of visits to these places.

\subsubsection{Exploring metadata}

To study the temporal variations of Biarritz's visitor numbers through Instagram data, ideally access is needed to the temporal information of the photographs taken. This datum can be stored in EXIF (Exchangeable Image File) data, associated with the image. Automatically recorded by the device, they correspond to a set of data relating to each digital photograph and presented in a standardised format. However, for privacy reasons, this data is deleted when the photo is loaded onto the platform and is therefore not accessible when the data is downloaded. However, the metadata associated with each post provides timestamp type information which corresponds to the time of posting [17].

For each of our explorations, we will compare two geographic scales: Biarritz in general (with the whole corpus), and four well-known places in the city, namely the Rocher de la Vierge, symbol of the coastline, the Casino Barrière, emblematic of the city's tourist practice, the Grande Plage, an exceptional site for surfing, and the Biarritz Aquarium, whose visits theoretically depend less on the season and weather. 
The exploration of the monthly variation (Fig. 2) confirms the importance of the seasonality of the tourist city with an increase in the number of posts from May to August, which is the expected peak, and its gradual decline through until autumn. The low season appears between January and March. Thus, on the scale of Biarritz, this study seems to validate the hypothesis that the number of posts on Instagram is a reliable indicator of the seasonality of the seaside tourist city. On the scale of the different places, we can see a similar trend but with specificities: the Grande Plage has two peaks: May (World Longboard Surfing Championships) and August. The Casino Barrière, is generally little present on the social medium in comparison with the other sites, has a fairly uniform visibility throughout the year but soars in December, probably due to the Christmas and New Year celebrations. The Aquarium and the Rocher de la Vierge have a visibility curve similar to that of the city with a peak in August.

We conclude this exploration by looking at the daily variations and the hours of posting on the Instagram site (Fig. 3). A general peak occurs in late afternoon around 5-6 p.m. The curve is quite similar for each place studied, even though we were expecting longer lulls at

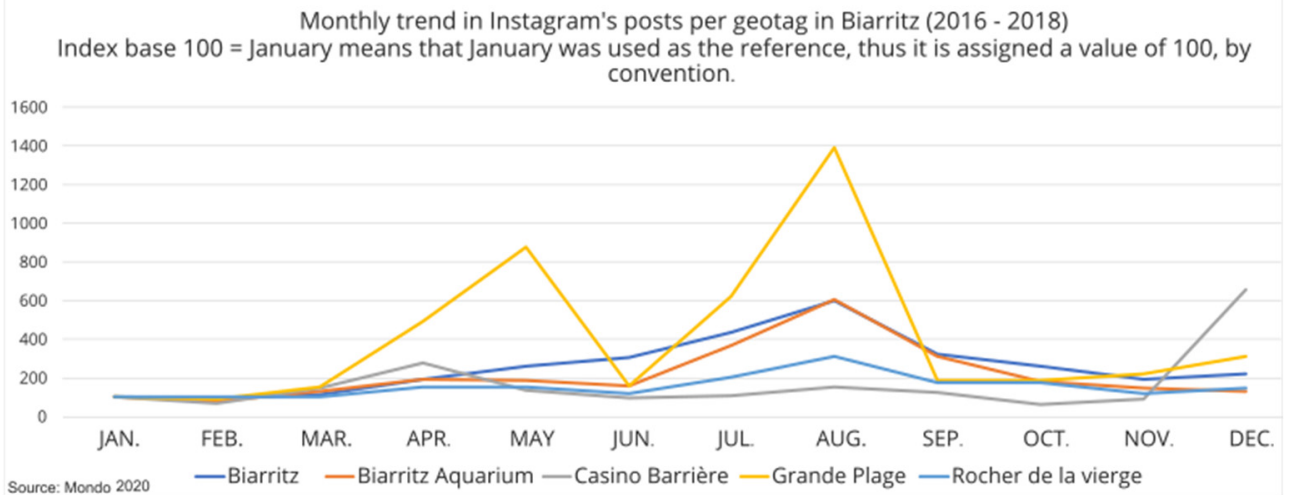

Figure 2: Monthly trend in Instagram's posts per geotag in Biarritz (2016-2018) (index 100 = January). (Source: Author, 2020.)

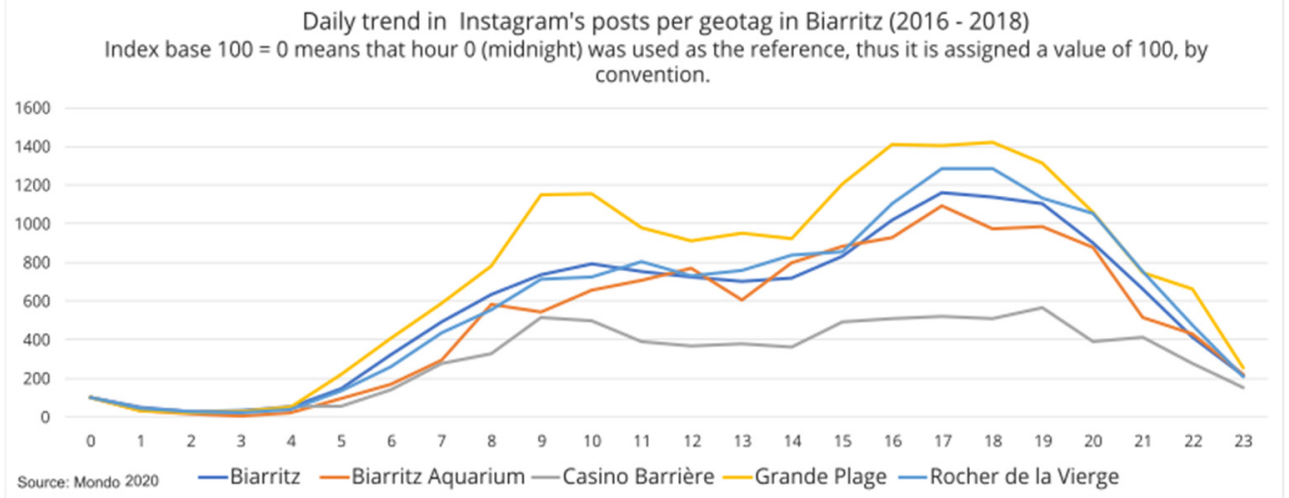

Figure 3: Daily trend in Instagram's posts per geotag in Biarritz (2016-2018) (index 100 $=0$ h). (Source: Author, 2020.) 
the casino and the aquarium for example, which are not open-air sites and whose access opportunities are therefore restricted to opening times. Thus, the casino closes in the morning from 4 a.m. to 9 a.m., which is absolutely not evident on the curve. The aquarium has a first posting peak from 8 a.m., but there are also many posts made at 10 p.m., despite it being closed. These sites, located in the very centre of Biarritz, near the beaches, are therefore on the circuit of other activities and can be visited and/or photographed on several occasions. The photographs posted can be taken inside the buildings during the visits but also outside and therefore sometimes outside opening hours.

\subsubsection{Limits and new research opportunities}

Analysis of metadata on a fine time scale reveals a possible lag between the moment when the photograph is taken by the user and the moment when it is posted on the platform. Obviously, the photo may have been posted at the time it was taken, but it may also have been posted at a time when tourists are freer or when they take a break from walking around the city. But the uses can also be more calculated, and it is not uncommon to wait for an auspicious moment, in relation to the target audience, to post an image since the post will have varying degrees of visibility depending on the time of posting.

Some users can also choose to only post their photographs at the end of their stay, as we used to do traditionally with our photo albums. In any case, other than by examining the practices of the users concerned, it is not possible to identify the link between the exact moment the photograph was taken and the moment of its posting. The prospect of demonstrating the daily rhythm of the tourist city through Instagram data thus seems limited since the time studied does not necessarily correspond to the time spent on site.

However, an observation on other time and place scales is interesting since we can highlight the seasonal variations of the tourist city but also the specific characteristics of certain places within this city. The monthly observation also makes it possible to highlight peaks of interest for certain places corresponding to events.

\subsection{Observing the visibility of tourist places through digital footprints}

\subsubsection{Supposed contributions}

What does the data tell us about the visibility of places in the tourist city on Instagram? The visibility of a place or a practice feeds into and consolidates the tourist imaginary, yet it is no longer dependent solely on travel guides or institutions but is now fed into by each individual. The development of social media, their instantaneous nature and the fact that everyone can share their photos and opinions online have made it possible to multiply sources and reflect on the definition of the imaginary. By allowing individuals to represent a "place as an understandable tourist destination" [42], the tourist imaginary contributes to the attractiveness of the places.

The footprints left on Instagram must therefore allow us to identify the highlights of this tourist collective imagination of Biarritz: centred on the coast, and its emblematic sites such as the Rocher de la Vierge, the beaches, the Lighthouse or the Casino. These footprints will make it possible to outline, through their aggregation, envelopes of spatial practices of the tourist city. Since the footprints are also the fruit of diverse and varied profiles, we expect to see new places of visibility appear, embodying possible new hubs of attraction in the city.

\subsubsection{Exploring metadata}

We saw in the previous part that EXIF data was not available among the data retrieved on Instagram. In fact, the geolocation coordinates of where the photo was taken are also 
unavailable. The geographic tag of the image shared on social media then takes the form of a geotag, in other words, a place declared by the user from a predefined list or through manual entry. The hashtags associated with the images (such as \#biarritz, \#Pays Basque, \#restaurant) can sometimes reveal other geographic information but their automatic detection is more complex.

The study and mapping of geotags in our corpus shows an uneven distribution of posts (Fig. 4). The maximum is 46,880 posts for the "Côte des Basques" geotag, followed by the "Rocher de la Vierge" $(11,251)$ and the "Biarritz lighthouse" $(8,830)$. Thus, there are no surprises when it comes to the most represented places. But we also find unexpected places such as a night club (Duplex Club Biarritz), or restaurants (Etxola Bibi or Le Surfing). Therefore, although we can identify many emblematic places, it is also possible to witness the appearance of other types of places that are more urban and not specifically touristy but that are nonetheless specific to the most common practices on Instagram: restaurants, bars and other places of social interaction. This visibility can largely be explained by the way photographs are shared on Instagram: we tag what is "instagrammable", we photograph what can be tagged and we share what will give the account visibility.

Outside the visible places, whether they are expected or not, we can focus on the white of the map. There are the expected invisible features, outside the centre. These concern neighbourhoods that are a priori more residential and less attractive, without any particularly remarkable places. But certain characteristic places are rendered invisible by this map, like the golf course near the Biarritz lighthouse: no footprint emerges from our database, whereas it is an extensive area, visited by many people. This invisibility can be explained by a possible

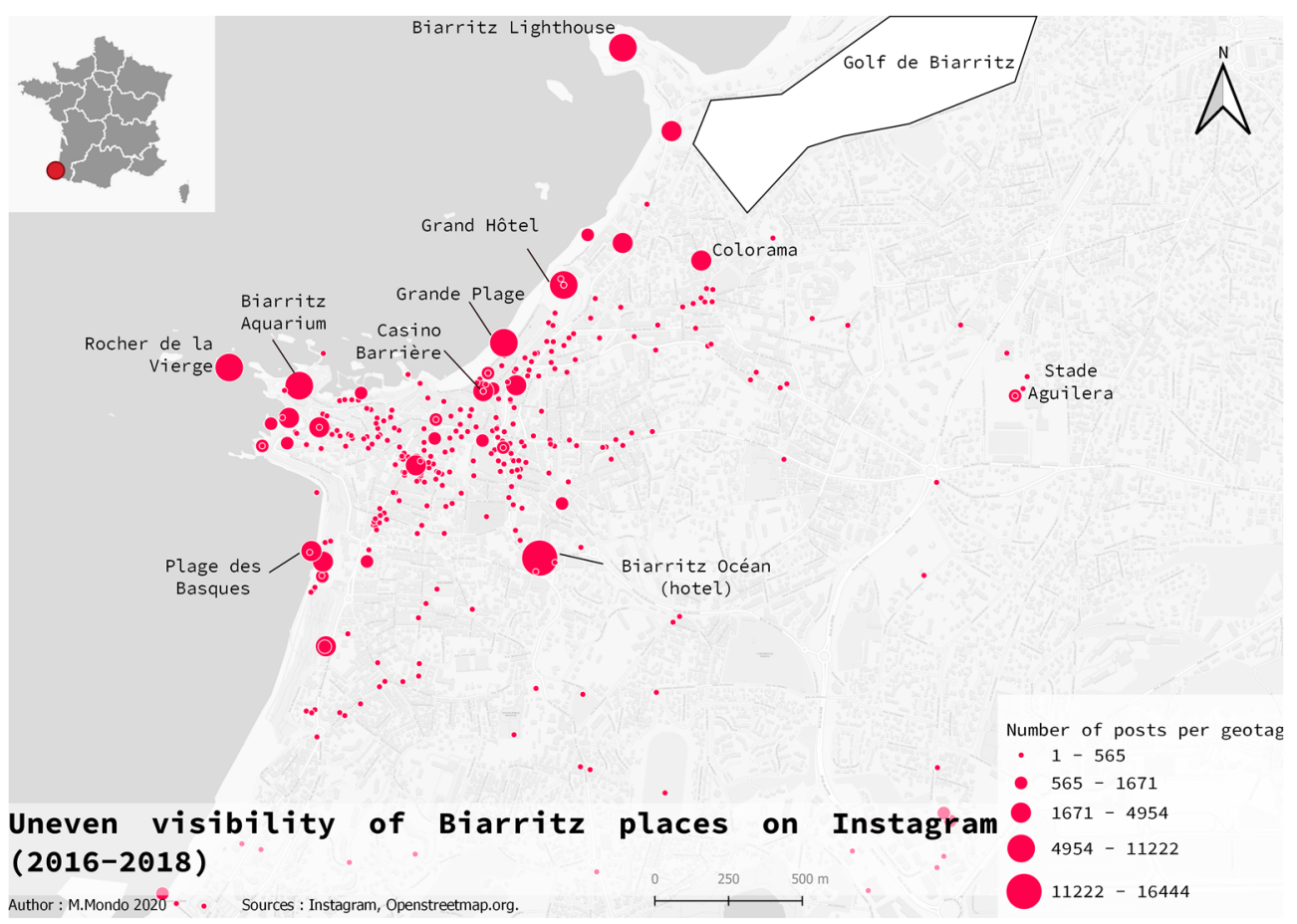

Figure 4: Uneven visibility of Biarritz places on Instagram (2016-2018). (Source: Author, 2020.) 
divergence between the profile of users of the place and that of Instagram users, or because the Instagram algorithm did not incorporate it into places in Biarritz.

\subsubsection{Limits and new research opportunities}

Other places have surprising visibility, such as "Biarritz Océan" which stands on the outskirts of the city centre. This example is particularly illustrative of the limits of the automatic geolocation of geotags. Biarritz Océan is a hotel residence, but it is also the name given to the complex comprising the Aquarium and the Cité de l'Océan in Biarritz. However, the Cité de l'Océan museum is barely visible on this map. It is therefore possible that the two geotags with similar names were confused at the time of geocoding. In addition, during a stay in the field in May 2019, we noticed the presence in a disused garage of works of street art that were presented during the annual Colorama festival. We therefore sought to locate it in order to compare its official location in relation to our field exploration, but the two do not correspond. Indeed, certain geotags are linked to events (exhibitions, festival) more than to specific and unique places, all the more so when these events are temporary. Thus, the locations may not correspond from one year to the next and the year and the geotag would have to be made to coincide in order to have more precise information. So, even if the geotag corresponds to the identity of the place photographed, it does not necessarily correspond to its actual location.

The difficultly in distinguishing between frequented, visited and photographed places is also one of the original features of the Instagram approach in that points of interest are located by looking at the object staged, and not by strictly locating the object photographed. Although this limits an initial form of geographic analysis of these places it also allows us to examine the visibility and attractiveness of places differently.

\section{CONCLUSION}

Coming under critical data studies, this research shows that there is a divergence between the assumed contributions and the actual contributions of the digital footprints, particularly for understanding the space-time of the tourist city. Indeed, retrieving data from social media does not really constitute an alternative to the conventional collection of data to track visitor numbers in the tourist city over time. The data is complex to process and interpret, even if it gives rise to abundant public dissemination in the form of heatmaps that are difficult to interpret and to opaque methodologies. Even by following the trail back to the source of the data, these digital footprints are less calibrated than those collected during specific surveys conducted directly with visitors. They are also less precise than observation in the field, especially when it comes to defining the daily time frames of visitor numbers at places.

However, this divergence offers other perspectives for research into the tourist city. These digital footprints make it possible to highlight unprecedented time frames of tourist practice such as the moments devoted to sharing photographs on social media. In addition, data from Instagram shapes a more complex tourist imaginary by increasing the visibility of more banal or less expected places, whose only recognition comes from social media. Conversely, by default, they allow mapping of parts of the tourist city that do not appear on a social medium dedicated to sharing photographs.

It is however essential to go further in the exploration of this database. To learn more about tourism practices, a categorisation of Instagram users should be proposed, making it possible to distinguish a group of individuals termed "tourists". By associating the question of the individual with that of time and space, it will then be possible to approach tourism in these three constitutive dimensions and so see how, on the basis of the study of journeys outside everyday space, the tourist city participates in the recreation of individuals. 


\section{ACKNOWLEDGEMENT}

This study was carried out as part of the DA3T project, funded by the Nouvelle-Aquitaine region (France).

\section{REFERENCES}

[1] Lodders, A., Miller, T. \& Paterson, J., The cost to freedom in the war against Covid19. Pursuit, University of Melbourne, 5 Apr. 2020.

[2] Subbiaco, C., Cosi big data e intelligenza artificiale scoprono chi fugge dalla quarentena. Il Digitale, 22 Mar. 2020.

[3] González, M.C., Hidalgo, C.A. \& Barabási, A.-L., Understanding individual human mobility patterns. Nature, 453(7196), pp. 779-782, 2008. DOI: 10.1038/nature06958.

[4] Ratti, C., Frenchman, D., Pulselli, R.M. \& Williams, S., Mobile landscapes: Using location data from cell phones for urban analysis. Environ. Plann. B Plann. Des., 33(5), pp. 727-748, 2006. DOI: 10.1068/b32047.

[5] Fournier, C. \& Jacquot, S., Les traces numériques des touristes. Un renouvellement de l'observation touristique? Espaces Tourismes et Loisirs, 316, pp. 66-71, 2014.

[6] Kitchin, R. \& Lauriault, T., Towards critical data studies: Charting and unpacking data assemblages and their work. SSRN Scholarly Paper ID 2474112, 2014. https://papers.ssrn.com/abstract=2474112. Accessed on: 29 May 2020.

[7] Diminescu, D. \& Wieviorka, M., Le défi numérique pour les sciences sociales. Socio, 4, pp. 9-17, 2015. DOI: 10.4000/socio. 1254.

[8] Goodchild, M.F., Citizens as sensors: the world of volunteered geography. GeoJournal, 69(4), pp. 211-221, 2007. DOI: 10.1007/s10708-007-9111-y.

[9] Crampton, J.W. et al., Beyond the geotag: Situating "big data" and leveraging the potential of the geoweb. Cartography and Geographic Information Science, 40(2), pp. 130-139, 2013. DOI: 10.1080/15230406.2013.777137.

[10] Tovar, E., Mesurer la justice socio-spatiale: de l'ancien au nouveau monde, promesses et menaces du "Big Data". Justice Spatiale (Spatial Justice), 10, p. 24, 2016.

[11] Jolivet, L., Guilcher, A.L., Mustière, S., Olteanu-Raimond, A.-M. \& Touya, G., Potentiel des données géolocalisées issues de la foule pour les questions de mobilité et tourisme: quelques exemples issus de la littérature. IGN, Research Report, Jan. 2017. Accessed on: 29 May 2020. https://halshs.archives-ouvertes.fr/halshs-02346056.

[12] Li, J., Xu, L., Tang, L., Wang, S. \& Li, L., Big data in tourism research: A literature review. Tourism Management, 68, pp. 301-323, 2018.

DOI: 10.1016/j.tourman.2018.03.009.

[13] Jacquot, S., Chareyron, G. \& Cousin, S., Le tourisme de mémoire au prisme du "big data". Cartographier les circulations touristiques pour observer les pratiques mémorielles. Tourisme, 14, 2018. DOI: 10.4000/tourisme.1713.

[14] Girardin, F., Calabrese, F., Fiore, F.D., Ratti, C. \& Blat, J., Digital footprinting: uncovering tourists with user-generated content. IEEE Pervasive Comput., 7(4), pp. 36-43, 2008. DOI: 10.1109/MPRV.2008.71.

[15] Cousin, S., Chareyron, G., Da-Rugna, J. \& Jacquot, S., Étudier TripAdvisor. Ou comment Trip-patouiller les cartes de nos vacances. EspacesTemps.net, 2014. Accessed on: 25 Jun. 2018. www.espacestemps.net/articles/etudier-tripadvisor/.

[16] Salas-Olmedo, M.H., Moya-Gómez, B., García-Palomares, J.C. \& Gutiérrez, J., Tourists' digital footprint in cities: Comparing Big Data sources. Tourism Management, 66, pp. 13-25, 2018. DOI: 10.1016/j.tourman.2017.11.001.

[17] Hochman, N. \& Manovich, L., Zooming into an Instagram city: Reading the local through social media. First Monday, 18(7), 2013. DOI: 10.5210/fm.v18i7.4711. 
[18] Branchet, B., Chareyron, G., Cousin, S., Da-Rugna, J., Michaud, M. \& Piñeros, S., Observer les pratiques touristiques en croisant traces numériques et observation ethnographique. Le projet de recherche Imagitour. Espaces Tourismes et Loisirs, 316, pp. 105-113, 2014.

[19] Boy, J. \& Uitermark, J., Reassembling the city through Instagram. Trans. Inst. Br. Geogr., 42(4), pp. 612-624, 2017. DOI: 10.1111/tran.12185.

[20] Genevois, S., Quels apports du Géoweb et de la géolocalisation pour représenter les mobilités touristiques? M@ppemonde, 124,p. 10, 2018.

[21] García-Palomares, J.C., Gutiérrez, J. \& Mínguez, C., Identification of tourist hot spots based on social networks: A comparative analysis of European metropolises using photo-sharing services and GIS. Applied Geography, 63, pp. 408-417, 2015.

DOI: $10.1016 /$ j.apgeog.2015.08.002.

[22] Nikitopoulos, P., Paraskevopoulos, A.-I., Doulkeridis, C., Pelekis, N. \& Theodoridis, Y., Hot spot analysis over big trajectory data. 2018 IEEE International Conference on Big Data (Big Data), Seattle, WA, pp. 761-770, 2018.

DOI: 10.1109/BigData.2018.8622376.

[23] Shoval, N. \& Ahas, R., The use of tracking technologies in tourism research: The first decade. Tourism Geographies, 18(5), pp. 587-606, 2016.

DOI: $10.1080 / 14616688.2016 .1214977$.

[24] Mericskay, B., Noucher, M. \& Roche, S., Usages des traces numériques en géographie: Potentiels heuristiques et enjeux de recherche. L'Information géographique, 82(2), pp. 39-61, 2018. DOI: 10.3917/lig.822.0039.

[25] Thatcher, J., Big Data, big questions: Living on fumes: digital footprints, data fumes, and the limitations of spatial Big Data. International Journal of Communication, 8(19), 2014.

[26] Dalton, C.M., Taylor, L. \& Thatcher, J., Critical data studies: A dialog on data and space. Big Data and Society, 3(1), 2016. DOI: 10.1177/2053951716648346.

[27] Burns, R., Datafying disaster: Institutional framings of data production following Superstorm Sandy. Annals of the American Association of Geographers, 108(2), pp. 569-578, 2018. DOI: 10.1080/24694452.2017.1402673.

[28] Beaude, B., Spatialités algorithmiques. Traces numériques et territoires, Presses des Mines: Paris, pp. 135-162, 2015.

[29] Noucher, M., Que reste-t-il de Friday Harbor? Pour une approche critique renouvelée des usages du géoweb fondée sur l'analyse des traces numériques. Rev. Int. Geomat., 28(1), pp. 15-37, 2018. DOI: 10.3166/rig.2017.00036.

[30] Urru, J. \& Larsen, J., The Tourist Gaze 3.0, 3rd ed., SAGE: London, 2011.

[31] Soissons, D. \& Eyraud, H., La photo, un support de communication de plus en plus exigeant. Espaces Tourismes et Loisirs, 322, pp. 23-28, 2015.

[32] Larsen, J., Families seen sightseeing: Performativity of tourist photography. Space and Culture, 8(4), pp. 416-434, 2005. DOI: 10.1177/1206331205279354.

[33] De Paillette, S., Image, tourisme et territoire. Trompe-l'œil ou cercle vertueux? Espaces Tourismes et Loisirs, 322, pp. 14-23, 2015.

[34] Amirou, R., L'imaginaire touristique, new ed., CNRS Édition: Paris, 2012.

[35] We are Social, Digital 2020: Global digital overview, 2020. https://wearesocial.com/digital-2020. Accessed on: 25 May 2020.

[36] Piganiol, V., Instagram, outil du géographe? Cybergeo: European Journal of Geography, 2017. http://journals.openedition.org/cybergeo/28832. Accessed on: 29 Apr. 2020.

[37] Augustin, J.-P., Surf Atlantique: les territoires de l'éphémère, MSHA: Pessac, 1994. 
[38] Ville de Biarritz, Biarritz en chiffres. Site internet de la ville de Biarritz, 2020. https://ville.biarritz.fr/ma-ville-nere-hiria/decouvrir-biarritz/biarritz-en-chiffres425.html. Accessed on: 13 May 2020.

[39] Newton, C., Instagram is getting rid of photo maps. The Verge, 6 Sep. 2016. www.theverge.com/2016/9/6/12817340/instagram-photo-map-removals. Accessed on: 21 Oct. 2019.

[40] Gwiazdzinski, L., La ville 24 heures sur 24, Rhutmos: Paris, 2016.

[41] Lucchini, F., Temporalités et rythmes urbains: les interprétations géographiques du temps et les espaces urbains. L'Information géographique, 79(2), pp. 28-40, 2015. DOI: 10.3917/lig.792.0028.

[42] Gravari-Barbas, M. \& Graburn, N., Imaginaires touristiques. Via. Tourism Review, 1, 2012. Accessed on: 29 May 2020. http://journals.openedition.org/viatourism/1178.

[43] Maptimize, \#onemilliontweetmap, 2020. https://onemilliontweetmap.com/. 